\title{
Crater Statistics on the Dark-Toned, Mafic Floor Unit in Jezero Crater, Mars
}

Shahrzad, Stephanie; Kinch, Kjartan M.; Goudge, Timothy A.; Fassett, Caleb I.; Needham, Debra H.; Quantin-Nataf, Cathy; Knudsen, Cecillie P.

Published in:

Geophysical Research Letters

DOI:

10.1029/2018GL081402

Publication date:

2019

Document version

Publisher's PDF, also known as Version of record

Citation for published version (APA):

Shahrzad, S., Kinch, K. M., Goudge, T. A., Fassett, C. I., Needham, D. H., Quantin-Nataf, C., \& Knudsen, C. P. (2019). Crater Statistics on the Dark-Toned, Mafic Floor Unit in Jezero Crater, Mars. Geophysical Research Letters, 46(5), 2408-2416. https://doi.org/10.1029/2018GL081402 


\section{Geophysical Research Letters}

\author{
RESEARCH LETTER \\ 10.1029/2018GL081402 \\ Key Points: \\ - Based on craters $177-500 \mathrm{~m}$ we \\ estimated the model age of the \\ dark-toned floor unit as $2.6 \pm 0.2 \mathrm{Ga}$ \\ in the Hartmann system \\ - With $25 \%$ as an estimate of the \\ uncertainty associated with \\ identifying and measuring \\ diameters, we find a model age \\ range of $2.6 \pm 0.5 \mathrm{Ga}$ \\ - The average thickness of the unit at \\ the margins is determined to be \\ $\sim 13.0 \pm 0.8 \mathrm{~m}$
}

Supporting Information:

- Supporting Information S1

- Data Set S1

- Data Set S2

Correspondence to:

S. Shahrzad,

qxr806@alumni.ku.dk

Citation:

Shahrzad, S., Kinch, K. M., Goudge, T. A., Fassett, C. I., Needham, D. H., Quantin-Nataf, C., \& Knudsen, C. P. (2019). Crater statistics on the dark-toned, mafic floor unit in Jezero crater, Mars. Geophysical Research Letters, 46, 2408-2416. https://doi.org/ 10.1029/2018GL081402

Received 27 NOV 2018 Accepted 8 FEB 2019 Accepted article online 13 FEB 2019 Published online 11 MAR 2019

\section{Crater Statistics on the Dark-Toned, Mafic Floor Unit in Jezero Crater, Mars}

\author{
Stephanie Shahrzad ${ }^{1}$ (D), Kjartan M. Kinch ${ }^{2}$ iD, Timothy A. Goudge ${ }^{3}$ iD, Caleb I. Fassett ${ }^{4}$ (D), \\ Debra H. Needham ${ }^{4}$ (D), Cathy Quantin-Nataf ${ }^{5}$, and Cecillie P. Knudsen ${ }^{2}$ (D) \\ ${ }^{1}$ Department of Geosciences and Natural Resource Management, University of Copenhagen, Copenhagen, Denmark, \\ ${ }^{2}$ Niels Bohr Institute, University of Copenhagen, Copenhagen, Denmark, ${ }^{3}$ Jackson School of Geosciences, University of \\ Texas at Austin, Austin, TX, USA, ${ }^{4}$ NASA Marshall Space Flight Center, Huntsville, AL, USA, ${ }^{5}$ Laboratoire de Géologie de \\ Lyon, Terre, Planètes, Environnement, Université de Lyon-Université Claude Bernard, Villeurbanne, France
}

Abstract Jezero crater is a $\sim 45-\mathrm{km}$ impact crater on the margin of Isidis basin on Mars. Jezero is the landing site for NASA's Mars 2020 rover mission. The crater hosts a paleolake, and fluvio-lacustrine deposits formed in this lake remain accessible to exploration. A dark-toned deposit on the crater floor overlies light-toned carbonate-bearing deposits and has been interpreted as a lava flow. We determined the average thickness of this deposit at the margins to be $\sim 13.0 \pm 0.8 \mathrm{~m}$. We analyzed the statistics of impact craters superposed on this deposit and estimated its model age as $2.6 \pm 0.5 \mathrm{Ga}$ in the Hartmann system, placing it most likely in the Early Amazonian. The error estimate here includes an estimate of the uncertainty associated with the crater counts. Acquisition, caching, and eventual return of a sample from this unit could provide an important calibration point for Mars crater chronology.

Plain Language Summary Jezero crater is a large impact crater on Mars with a diameter of about $45 \mathrm{~km}$. In the Martian deep past this crater hosted a long-lived lake. On 19 November NASA announced that Jezero crater will be the landing site for the coming Mars 2020 mission. On top of sediments on the central crater floor is a distinctive deposit of dark rocks that possibly originated as a lava flow after the lake had dried out. We studied the statistics of small impact craters on this dark deposit. Such impact crater statistic is widely used as a tool for dating Martian terrains. We report a derived "model age" of $2.6 \pm 0.2 \mathrm{Ga}$ for these rocks. One central goal of the Mars 2020 mission is to select and store a cache of rock samples that will be returned to Earth by a later mission for study in terrestrial laboratories. If this dark deposit is indeed lava, a sample could be dated in terrestrial laboratories. Together with our crater statistics reported here, this could provide a crucial tie-point for recalibration of the crater count dating system for Mars, which now relies on extrapolation from samples collected on the Moon.

\section{Introduction}

Jezero crater is a $\sim 45-\mathrm{km}$-diameter Martian impact crater. The crater is located at $18^{\circ} \mathrm{N} 77^{\circ} \mathrm{E}$, on the western margin of the Isidis basin (Schultz \& Frey, 1990), southeast of the ancient Noachian terrain (Mangold et al., 2007; Mustard et al., 2009) around the Nili Fossae graben system (Comer et al., 1995; Wichman \& Schultz, 1986) and northeast of the Hesperian-age Syrtis Major volcanic province (Hiesinger $\&$ Head, 2004). Jezero crater is the site of a paleolake (Fassett \& Head, 2005), with two valley networks from the north and the west terminating in the basin, and likely delta deposits exposed within the crater at the mouths of the two inlets (Fassett \& Head, 2005; Goudge et al., 2017). In addition, there is an outlet valley to the east with a valley floor elevation $\sim 250 \mathrm{~m}$ above the crater floor indicating a hydrologically open system (Fassett \& Head, 2005).

Jezero crater is an attractive site for in situ exploration (Goudge et al., 2017; Schon et al., 2012) and on 19 November 2018, NASA announced the selection of Jezero crater as the landing site for the Mars 2020 rover mission. One of the draws of Jezero crater as a landing site is the presence of a dark-toned unit emplaced inside the crater. The dark-toned unit exhibits spectral signatures of high-calcium and low-calcium pyroxene and has been hypothesized to be volcanic in origin (Goudge et al., 2012, 2015; Schon et al., 2012). This unit is of interest as a place to potentially sample primary igneous rock that would provide insight into the Martian mantle reservoir under the Syrtis Major region. In addition, acquisition, caching, and returning a sample of 
this unit to Earth for radiometric age dating would be valuable to constrain the absolute timing of crater production functions used widely across Mars for terrain dating.

Two different crater-count age determinations for this dark-toned floor unit exist in the literature: An Early Amazonian age of $1.4 \mathrm{Ga}$ (Schon et al., 2012) and an Early Hesperian age of $3.45 \pm_{0.67}^{0.12}$ Ga (Goudge et al., 2012). Both of the previously published ages are from works whose primary focus lay elsewhere, and neither provide extensive discussion of the age determination. Due to the interest in Jezero crater as a site for in situ exploration, including specific interest in the dark-toned floor unit, a thorough study of the crater statistics of the dark-toned unit in Jezero crater is warranted and necessary to resolve discrepancies in previous age determinations. Here we present new crater counts and age determination results for this geologic unit, including an analysis of the spatial distribution of craters on the unit and a discussion of discrepancies between model ages and their potential explanation. We focus purely on the emplacement age of the unit and do no not directly address its nature, which could be lava, ash, or basaltic sandstone without changing our conclusions.

\section{Methods}

\subsection{Data and Morphology}

For the outline of the dark-toned floor unit, we used the mapping created by Goudge et al. (2015) after manually verifying the contacts. The dark unit is distinctive and easy to distinguish from surrounding terrain by criteria of low albedo and a surface texture devoid of polygonal fracture patterns that are prominent in the underlying unit. The boundary of the unit is also marked by an elevation change, and the surface of the dark-toned unit is higher than the surrounding terrain. We measured this elevation difference in 410 locations around the edges of the unit using DEMs (digital elevation models) from the HiRISE (High Resolution Imaging Science Experiment; McEwen et al., 2003) instrument produced using the NASA Ames Stereo Pipeline (Beyer et al., 2018; Shean et al., 2016). In addition, CTX (Context Camera) (Dickson et al., 2018; Malin et al., 2007) images were used to verify the mapping and to identify large craters outside of the area covered by HiRISE. The mapping and crater counts were performed in an equidistant cylindrical projection centered at $77.69^{\circ} \mathrm{E}, 18.388^{\circ} \mathrm{N}$.

\subsection{Crater Counting and Spatial Distribution}

The craters were mapped using HiRISE DEMs in ArcMap (McEwen et al., 2007) as the background. Though the HiRISE images do not cover the entire unit, the resolution of down to $30 \mathrm{~cm} / \mathrm{pixel}$ (McEwen et al., 2003) and DEMs were necessary to resolve the craters on highly eroded parts of the unit. In areas where the HiRISE frames overlapped, the frame we use is marked in Figure 1. A list of the HiRISE frames is found in Table S2 in the supporting information. The HiRISE and CTX images were loaded into the GIS program ArcMap. Craters were mapped using the CraterTools (Kneissl et al., 2011) plug-in to ArcMap, where each crater was marked using three points along the rim to create a circle. Following standard procedures for crater mapping, all recognizable craters were counted regardless of their state of degradation (Melosh, 2011). We counted all craters on the parts of the dark-toned unit that had HiRISE coverage. Craters 150-500 m were counted, but the analysis included only craters $>177 \mathrm{~m}$ in order to avoid any systematic error related to the lower size boundary used in counting (177 $\mathrm{m}$ is a bin boundary in the fourth-root- 2 scheme we use). Two independent counts were performed by two different workers using the same data and approach. In addition, we performed a separate count of craters $>500 \mathrm{~m}$ using the CTX map of the entire unit (area within solid black line in Figure 1). The lists of craters created in ArcMap were imported into the program Craterstats v.2 (Michael, 2013; Michael \& Neukum, 2010). Craterstats was used to display and analyze the crater size-frequency distribution of the data and to calculate a model age for the dark-toned unit.

In order to investigate whether the spatial distribution of mapped craters is consistent with random accretion of primary impacts on a geologic unit with a single well-defined age, we performed a simple $\chi^{2}$ test on the distribution of craters $<500 \mathrm{~m}$ on the nine HiRISE frames. We performed this test both on craters $>177 \mathrm{~m}$ in diameter and on craters $>150 \mathrm{~m}$ in diameter. This test should reveal significant large-scale clustering due to, for example, secondary impacts or due to age differences within the unit or to significant differential erosion. 


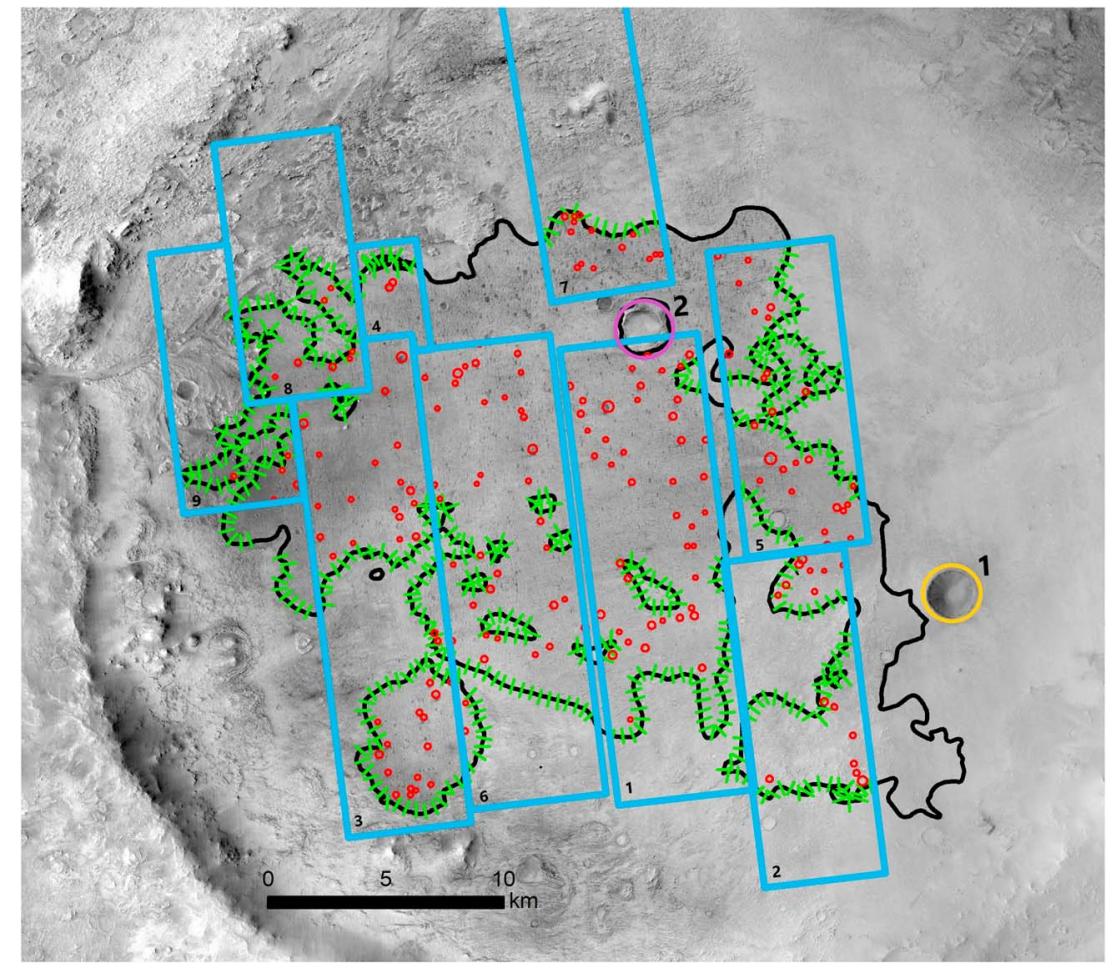

Figure 1. CTX image of Jezero crater. The black outlines the dark-toned floor unit, with all the counted craters $(>177 \mathrm{~m}$ diameter) marked in red. Locations where unit thickness was measured are referenced with a green line. The blue squares outline the HiRISE tiles used to measure profiles and for crater counting. For specific HiRISE frame IDs, refer to Table S1 in the supplementary material. Crater 1 is marked by a yellow circle and Crater 2 is marked by a purple circle. CTX mosaic E76_N16 from (Dickson et al., 2018). CTX = Context Camera; HiRISE = High Resolution Imaging Science Experiment.

\section{Results}

\subsection{Morphology}

The edge thickness of the unit was measured in ArcMap, creating profiles crossing the unit boundary every $400 \mathrm{~m}$. This resulted in $\sim 410$ profiles, which recorded the elevation difference between the dark-toned floor unit and the underlying light-toned unit. An example of an elevation profile can be found in the supporting information in Figure S1. We interpreted this as the thickness of the dark-toned floor unit. By averaging the profiles, we found the average thickness of the unit at the margins to be $\sim 13.0 \pm 0.8 \mathrm{~m}$. For comparison, Schon et al. (2012) estimated a thickness of 10-30 m based on a similar analysis, and Goudge et al. (2015) reports a thickness of $<10 \mathrm{~m}$.

The simple-to-complex transition on Mars occurs at diameters between 3 and $8 \mathrm{~km}$ (Pike, 1981), with an estimated global average $\sim 6 \mathrm{~km}$ (Robbins \& Hynek, 2012). Since all mapped craters were $<2 \mathrm{~km}$ in diameter, they can all be safely assumed to have originally formed with the geometry of pristine simple craters. Pristine simple craters have a depth of about $20 \%$ (or 1/5) of the crater diameter and a rim elevated about $4 \%$ (or 1/25) of the crater diameter above the surrounding terrain (Cintala \& Mouginis-Mark, 1980; Daubar et al., 2014; Melosh, 2011; Pike, 1981). Using this estimate and the average floor unit thickness estimate of $13.0 \pm 0.8 \mathrm{~m}$, we suggest that craters with diameters above $\sim 325 \mathrm{~m}$ would be expected to form with rims higher than the typical thickness of the dark-toned floor unit. Considering the uncertainties involved, this number is obviously a rough estimate, but it still seems prudent to keep in mind that craters with diameters above $\sim 325 \mathrm{~m}$ in size may not have been erased by emplacement of the dark-toned unit and are therefore suspect for dating this event. Certainly, this is true for the largest crater (referred to as Crater 2 on Figure 1) present within the unit, which has a diameter of $1.8 \mathrm{~km}$. This crater would have formed with a depth of $\sim 398 \mathrm{~m}$ and a rim height of $\sim 68 \mathrm{~m}$ and could easily predate emplacement of the dark-toned unit. Our main age determination uses craters $177-500 \mathrm{~m}$, but we also discuss how this compares to what would be derived from the statistics of larger craters. 


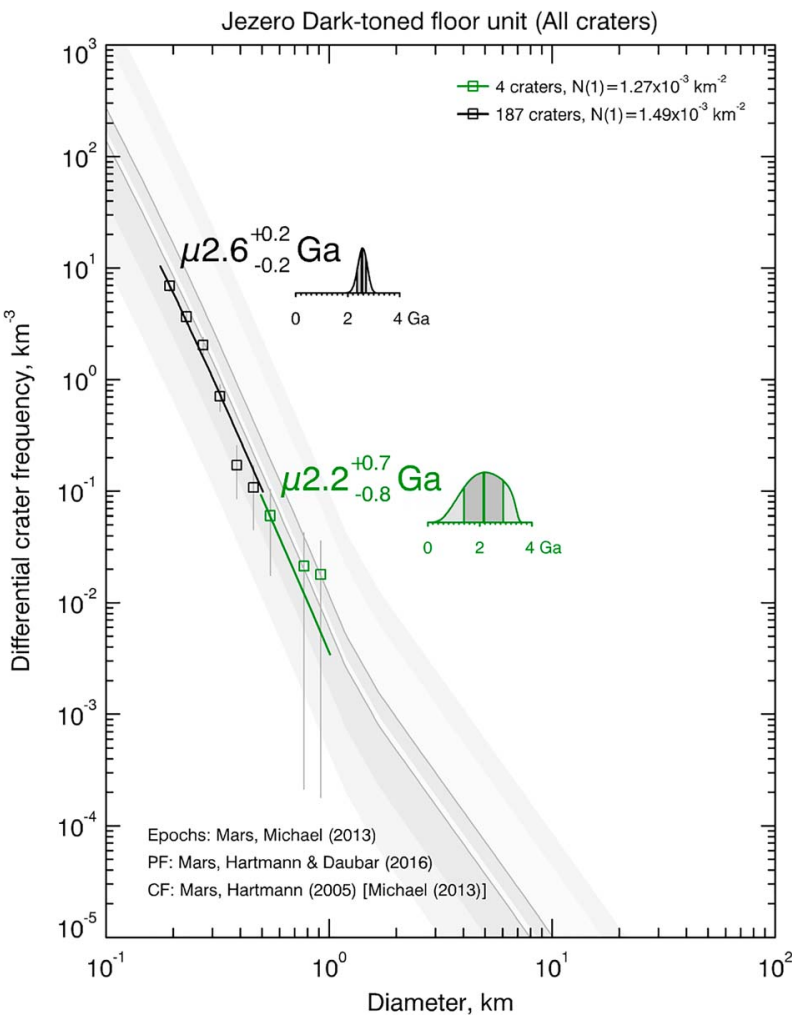

Figure 2. Craters plotted in a fourth-root-2 binning format. The black isochron is fitted with a Poisson fit (Michael et al., 2016) to craters with a diameter between 177 and $500 \mathrm{~m}$. This produced an age of $2.6 \pm 0.2 \mathrm{Ga}$. The green bins represent the craters $>500 \mathrm{~m}$ with a Poisson fit, which alone produces an age of $2.2+0.7,-0.8 \mathrm{Ga}$.
Based on the morphology of Crater 2 (Figure S3 in the supporting information) it is difficult to conclude if this crater predates or postdates the emplacement of the dark-toned unit. There are no clear superposition relationships with the dark-toned unit. The crater rim is not breached, which would have provided a firm indication that the crater predated emplacement of the dark-toned unit. On the other hand, Crater 2 lacks a preserved ejecta blanket or other impact-related features that would have clearly indicated that crater formation postdated the emplacement of the dark-toned floor.

However, the western wall of Crater 2 has a jagged contact with the darktoned floor unit, marked with blue arrows on Figure S3. This could potentially indicate a lava or pyroclastic flow that ran to the rim of the crater before stopping. In contrast, the eastern side of the crater displays a relatively smooth outer rim, with no clear contact to the dark-toned unit, as marked by the orange arrows on Figure S3. This lack of a clear contact could be due to the extensive sand coverage, shown by the aeolian bedforms on Figure S3 (orange arrows).

Another large crater within Jezero crater is marked as Crater 1 on Figure 1. This crater is shown in higher resolution in Figure S3 in the supporting information. This crater is located outside our mapped boundary of the dark-toned unit. Comparing Crater 1 to Crater 2, Crater 1 appears more pristine, with steep sides and a clearly identifiable and sharp rim. Crater 1 has a depth/diameter ratio of 0.20 , consistent with a pristine simple crater, whereas Crater 2 has a depth/diameter ratio of 0.055 , indicating significant erosion or infilling has occurred. Unlike Crater 2, Crater 1 has a distinct ejecta blanket. In our view the superposition relationship between the ejecta blanket and the dark-toned unit is ambiguous; this is perhaps unsurprising given the lack of contiguity between Crater 1 and the dark-toned unit.

We thus have no firm indication as to whether Crater 1 predates or postdates emplacement of the dark-toned unit.

Table S2 in the supporting information lists the seven craters $>500 \mathrm{~m}$ present on the unit together with an image and discussion of each of these craters, including their interpreted superposition relationship with the dark-toned unit. This table includes Crater 1, even though this crater is just outside the unit.

\subsection{Age}

In an area of $384 \mathrm{~km}^{2}$, we mapped 248 counted craters in two different measurements. The first was focused on mapping all craters between 150 and $500 \mathrm{~m}$ on the part of the unit with HiRISE coverage $\left(350 \mathrm{~km}^{2}\right)$. The last measurement focused on mapping all the $>500$ - $\mathrm{m}$ craters on the entire unit using CTX images in the area not covered by HiRISE $\left(384 \mathrm{~km}^{2}\right)$.

Of the 248 counted craters, 54 are $150-177 \mathrm{~m}, 187$ are $177-500 \mathrm{~m}$, and 7 craters are larger than $500 \mathrm{~m}$. We rejected three of the craters $>500 \mathrm{~m}$ from the statistics because we judged them to be predating emplacement, or for Crater 1, because the crater is outside the unit. Converted to frequencies our counts are equivalent to $N(>150 \mathrm{~m})=0.70$ craters $/ \mathrm{km}^{2}, N(>177 \mathrm{~m})=0.55 \mathrm{craters} / \mathrm{km}^{2}$, and $N(>500 \mathrm{~m})=0.011 \mathrm{craters} / \mathrm{km}^{2}$ (excluding three of the largest craters as mentioned). The raw count data, including crater center latitude/longitude and diameter, are available in the supporting information. For crater size-frequency analysis, the data were binned using the fourth-root-2. The binned data together with bin boundaries are also provided as Table S3 in the supporting information.

Figure 2 shows the differential crater size-frequency distribution for our data with two different fits. The 177to 500- $\mathrm{m}$ data are shown in the black isochron on Figure 2. The fit for the craters $>500 \mathrm{~m}$ is shown in green on Figure 2. 
Using a Poisson fit to our data (Michael et al., 2016), the production function of Hartmann and Daubar (2016) and the chronology function of Hartmann (2005), we find an absolute model age for the dark-toned unit's surface of $2.6 \pm 0.2 \mathrm{Ga}$ and an implied $N(>1 \mathrm{~km})$ value of the best fit isochron of 1,490 \pm 39 craters per million square kilometer. Note that the error quoted here is $\pm 1 \sigma$. Following the Werner and Tanaka (2011) revised chronology system, our results put the emplacement of the dark-toned floor unit in the Early Amazonian.

Including the largest craters $(>500 \mathrm{~m}$ ) in the age model for the $177-500 \mathrm{~m}$ craters does not change the age. Plotting only the four largest craters determined to superpose the unit (see supporting information Table S2) yields an age of $2.2+0.7,-0.8 \mathrm{Ga}$. This result is statistically indistinguishable from the $2.6 \pm 0.2-\mathrm{Ga}$ age. The same goes for fitting all seven large craters, which produces an age of $2.8+0.5,-0.7 \mathrm{Ga}$, still using the Poisson fit and the fourth-root-2 binning, which is also statistically consistent with the $2.6 \pm 0.2-\mathrm{Ga}$ age.

For comparison, a secondary counter also independently mapped all craters between 150 and $500 \mathrm{~m}$. The data were fit with a Poisson fit between 177 and $500 \mathrm{~m}$ with fourth-root-2 binning, exactly the same as the data on Figure 2. The result of this count was a model age of $2.2 \pm 0.2 \mathrm{Ga}$, which is not statistically consistent, but still fairly close and within the expected variation for counts by different workers. (Robbins et al., 2014). The isochron can be seen as Figure S2 in the supporting information.

\subsection{Spatial Distribution}

The total number of craters for each HiRISE frame is summarized in Table S1 in the supporting information together with the expected number of craters per frame. Assuming that the unit formed within a short period of time and has since randomly accumulated craters with no significant influence from clustered secondaries or craters being removed by erosion, the expected number of craters in each HiRISE frame is simply the total number of accumulated craters times the fraction of the total area of the unit that is contained in that frame:

$$
N_{i, e}=N_{\text {Total }} \cdot A_{i} / A_{\text {Total }}
$$

where $N$ is number of craters, $A$ is area, $i$ is an index denoting each separate HiRISE frame, and $e$ denotes the expected value. The number of craters should follow the Poisson distribution, and a standard $\chi^{2}$ test will determine whether the distribution of craters on the nine frames is statistically consistent with the model age. The $\chi^{2}$ test value is simply

$$
\chi^{2}=\sum_{i} \frac{\left(N_{i}-N_{i, e}\right)^{2}}{N_{i, e .}}
$$

For craters $177-500 \mathrm{~m}$ this test value is 8.67. Comparing to a $\chi^{2}$ distribution with eight degrees of freedom (nine HiRISE frames minus one free parameter-the total number of craters) this value is at the 63th percentile. About $62.6 \%$ of random cases would have craters more evenly distributed on the nine HiRISE frames. The major outlier is HiRISE frame \#7 where we count 14 craters against an expectation value of 8.05. This frame covers just a small area in the northeastern corner of the unit. The statistics are consistent with a random distribution. However, if we analyze instead all craters $>150 \mathrm{~m}$ the spatial distribution is clearly nonrandom. The test value in this case is 28.7 , far out in the tail of the distribution ( $>99.9 \%)$, and we must conclude that our collection of craters $150-500 \mathrm{~m}$ is not randomly distributed on the nine HiRISE frames. This supports the choice to use only craters $>177 \mathrm{~m}$ for dating. The culprit again is a large overcount in frame \#7 together with a smaller overcount in the neighboring frame \#5. For the secondary count, the distribution of $177-500 \mathrm{~m}$ craters is at the 85 th percentile (85.1\%) and for $150-500 \mathrm{~m}$ the value is again $>99.9 \%$. Primarily, again, due to a significant overcount in HiRISE frame \#7.

\section{Discussion}

\subsection{Small Craters}

Given the submeter resolution of the HiRISE data, craters down to a few tens of meters in diameter are clearly identifiable in the images. The lower diameter limit to what craters are useful for dating is thus not related to image resolution but rather to the geological processes of coverage and erosion that have 
affected the smallest craters on the unit. Counts of craters down to the limit of resolution on three small subregions indicated that the diameter at which the CSFD departs from the isochron varies from 50 to $100 \mathrm{~m}$ dependent on precise location. This suggests that at least counts of craters $<100 \mathrm{~m}$ are significantly affected by erosion or coverage by, for example, aeolian deposits. The spatial distribution analysis presented in section 3.3 shows that the data set of craters $150-500 \mathrm{~m}$ has a statistically significant nonuniform spatial distribution with higher crater frequencies in the northeastern corner of the unit. Restricting the data set to craters $177-500 \mathrm{~m}$, this tendency is still visible but no longer statistically significant. The main culprit is frame \#7, where there are about twice as many craters as would be expected. Nonetheless, this frame is small and the total count and resulting age determination is not dramatically affected by the counts in this frame.

Figure 2 shows that the craters $>177 \mathrm{~m}$ fall on a single isochron. The spatial distribution of these craters is consistent with a random distribution. From these observations, we argue that crater diameters $\geq 177 \mathrm{~m}$ can be meaningfully used for dating and that they date a specific event in the geologic history of Jezero crater. We hypothesize that this event is the emplacement of the dark-toned floor unit, which occurred in the Early Amazonian, with a derived model age of $2.6 \pm 0.2 \mathrm{Ga}$, where the error estimate is purely the statistical error. The higher-than-expected number of craters in the northeastern corner of the unit may indicate that the surface here in fact is older, or perhaps it is due to a cluster of secondary craters. The surface in this frame is very rough, and it is also possible that we have counted some features that are, in fact, not of impact origin. Nonetheless this area is fairly small and does not significantly impact the overall conclusions when restricted to craters $>177 \mathrm{~m}$ in diameter.

\subsection{Large Craters}

The derived age using craters $\geq 177 \mathrm{~m}$ is insensitive to whether or not the craters $>500 \mathrm{~m}$ are included in the fit, because the fit is dominated by smaller craters, and in both cases the data follow a single isochron across the full size range of counted craters. Based on the estimated thickness of the dark-toned unit, we hypothesize that some craters in the larger size range would likely not have been erased by emplacement of the unit, and thus some of these craters could well predate emplacement of the dark-toned unit. Regardless, the age determination for the craters $>500 \mathrm{~m}$ alone is statistically consistent with the derived age (i.e., $2.6 \mathrm{Ga}$ ) both when including all seven craters or when including only the four craters that we are confident postdate emplacement of the unit. Nonetheless, it is worth thinking more carefully about whether our derived age is wholly consistent with the presence of the very largest craters, namely, the 1.8-km diameter Crater 2 and/or the 2-km diameter Crater 1 .

We find no clear morphological indication that Crater 2 superposes the dark-toned floor unit, and indeed, there may be evidence that it predates the unit (Figure S3). The other large crater within the basin, the 2$\mathrm{km}$ diameter Crater 1, lies just outside the dark-toned floor unit, and it is ambiguous whether or not the ejecta from this crater superposes the unit (Figure S3).

Assuming the correctness of our modeled $N(>1 \mathrm{~km})$ result of 1,490 craters $>1 \mathrm{~km}$ on $10^{6} \mathrm{~km}^{2}$, the expected value is $1,430 \times 384 \mathrm{~km}^{2} / 10^{6} \mathrm{~km}^{2}=0.57$ craters above $1 \mathrm{~km}$ given the area of the dark-toned unit. Using the standard probability expression for the Poisson distribution,

$$
P(k)=\left(e^{-\lambda} \lambda^{k}\right) / k !
$$

(where $k$ is the number of craters and $\lambda$ is the expected value), we may ask, what is the likelihood of finding one or two craters larger than 1-km diameter superposed on a unit of this areal extent emplaced at this time? Inserting $k=0,1,2$ and $\lambda=0.57$, we find $P(0)=0.57, P(1)=0.32$, and $P(2)=0.092$. Thus, the likelihood of seeing no craters $>1 \mathrm{~km}$ is $57 \%$, the likelihood of one crater is $32 \%$, and the likelihood of seeing two craters is $\sim 9.1 \%$. The likelihood of three or more is $<2 \%$. In other words, while no craters would be most likely, seeing one crater (i.e., Crater 2 or Crater 1) larger than $1 \mathrm{~km}$ superposed on the unit is not unlikely and would happen in roughly one case out of three. Two craters would be more unusual but would still happen more than 1 case out of 11. Of course, Crater 1 is outside the mapped boundaries of this unit, so if Crater 1 were included, we would have to define some wider "buffered" area, and the likelihood of the occurrence would go up slightly (to perhaps 1 in 10). Seeing more than two craters would be unlikely.

To summarize, neither Crater 1 or 2 can be clearly identified as superposing the dark-toned unit. However, even if one of these craters does superpose the unit, the probability of having one such impact that postdates 
the unit is $\sim 32 \%$; two would be less likely, but not exceedingly so. Given the likelihood that either one, or both, of these impacts in fact predated emplacement of the dark-toned unit, their presence is fully consistent with the dark-toned unit's emplacement in the Early Amazonian. Given the pristine appearance of Crater 1 and the highly eroded appearance of Crater 2, we suggest that the most likely case is that Crater 1 postdates the unit while Crater 2 predates its emplacement.

\subsection{Error Estimates}

The error estimates reported in section 3.2 and Figure 2 are purely statistical errors, representing the natural uncertainty in rate estimation based on observed counts in a Poisson process. In addition to the statistical error, a model age determination is also affected by a "counting error" representing uncertainty associated with correctly identifying structures as craters and determining values for their diameters. Robbins et al. (2014) found that this uncertainty is at least $20 \%$ and up to $35 \%$ on particularly problematic surfaces. Applying a $25 \%$ error estimate to our counts results in an error estimate of $\pm 0.5 \mathrm{Ga}$. Adding the $\pm 0.2 \mathrm{Ga}$ statistical error in a root-mean-square sense and rounding, the error estimate is still \pm 0.5 to one significant digit. Thus, we give our model age estimate as $2.6 \pm 0.5 \mathrm{Ga}$, where the error estimate includes an estimate of the counting error. This implies a model age range from the early Amazonian into the late Hesperian. This error estimate still does not include the "model error," that is, uncertainty associated with the chronology function, which should also be included when interpreting the age as an absolute age, rather than as a relative age within the specific Mars chronology model.

\subsection{Comparison to Previous Age Determinations}

As described in section 1 there are two different ages published in the literature for the dark-toned unit in Jezero crater. The $3.45 \pm_{0.67}^{0.12} \mathrm{Ga}$ of Goudge et al. (2012) and the $1.4 \mathrm{Ga}$ of Schon et al. (2012). Here we have derived an age of $2.6 \pm 0.5 \mathrm{Ga}$ based on crater diameters $177-500 \mathrm{~m}$. Is it possible to reconcile these disparate ages?

The $3.45 \pm_{0.67}^{0.12}$ Ga Late Hesperian age from Goudge et al. (2012) was computed using the Ivanov (2001) chronology system; the equivalent age in the Hartmann system, used here and by Schon et al. (2012), is $3.35 \pm_{1.06}^{0.16}$ $\mathrm{Ga}$. This age is statistically consistent with our result within 1 standard deviation. The large error bars are due to the low number statistics. The age from Goudge was derived from five craters with diameters $>700 \mathrm{~m}$ found within Jezero crater. The differences between our model age result for large craters and the result from Goudge et al. (2012) can be accounted for by our exclusion of Craters 1 and 2 and to the different fit boundary. When including Craters 1 and 2 and fitting our data with diameters $>700 \mathrm{~m}$, we get a similar age to the Goudge et al. (2012) age, where our data produce an age of $3.5 \pm_{0.6}^{0.2} \mathrm{Ga}$.

The 1.4-Ga age for the dark-toned unit reported in Schon et al. (2012; Figure 6 of that paper) is derived from all craters above $200 \mathrm{~m}$ diameter using the Hartmann (2005) chronology system, similar to the system used for our result. Reanalysis of the Schon et al. (2012) count data suggests the age discrepancy is mainly due to a number of craters that cannot be clearly identified on CTX data but are visible in HiRISE-and particularly in HiRISE DEMs - and which we have counted here. In some cases, these craters are quite subtle and whether they are in fact impact craters, or perhaps erosional features, might be debatable.

\section{Conclusions}

We have mapped the dark-toned unit on the floor of Jezero crater and performed a count of superposed impact craters. We identified 248 superposed impact craters $>150 \mathrm{~m}$ in diameter.

Craters between 150 and $177 \mathrm{~m}$ in diameter are clearly nonrandom in spatial distribution, and we have excluded them. Craters 177-500 m are randomly distributed and give a consistent age that agrees well with the expected production function over at least a factor of 3 in diameter. Using a Poisson fit with fourth-root-2 binning and the Hartmann (2005) chronology system, we derive a model age of $2.6 \pm 0.5 \mathrm{Ga}$, where the error estimate is dominated by the counting error. We interpret this as the model age of emplacement of the darktoned floor unit, placing it in the Early Amazonian or possibly Late Hesperian. This relatively young formation age is consistent with the morphologically distinct nature of the dark-toned unit and its stratigraphic relationship to neighboring units. 
We determined the average thickness of the unit at the margin to be $13.0 \pm 0.8 \mathrm{~m}$ and argue that craters larger than $\sim 325 \mathrm{~m}$ in diameter may predate emplacement of the floor unit. Nonetheless, ages derived from craters $>500 \mathrm{~m}$ are statistically consistent with our derived age using craters $177-500 \mathrm{~m}$ in diameter.

Finally, we compare our results with earlier analyses by Goudge et al. (2012) and Schon et al. (2012). Goudge et al. (2012) were restricted to larger craters, and their results likely included craters that predated the unit of interest. The discrepancy in model age between this work and that earlier work is mainly due to uncertainties associated with low number statistics, and can specifically be accounted for by our rejection of Craters 1 and 2 and choice of fit boundary. Discrepancies between the results presented here and those from Schon et al. (2012) are best ascribed to the different data sets used, in particular our use of DEMs to identify some craters not clearly visible in CTX images. Clearly, the counting uncertainty is significant on this unit due to its small size and in some places rough surface texture; nonetheless we agree with Schon et al. (2012) in dating emplacement of the unit to (most likely) the Early Amazonian. Samples of this unit acquired and cached by NASA's Mars 2020 mission could provide a critical calibration point for the crater chronology of Mars when returned to Earth and radiometrically dated.

\section{Acknowledgments}

This work was funded in part by the Danish Council for Independent Research in the Natural Sciences, grant 4002-00292 and by the Carlsberg Foundation, grant CF16-0981. The data set that is the foundation of this work are images and digital elevation models (DEMs) from the High-Resolution Imaging Science Experiment (HiRISE) instrument on board the Mars Reconnaissance Orbiter. The list of the HiRISE images used is found in Table S1 in the supporting information, and they are available at the image catalog website (https://www.uahirise.org/ catalog/) hosted by The University of Arizona. Derived data from this paper can be found in the supporting information.

\section{References}

Beyer, R. A., Alexandrov, O., \& McMichael, S. (2018). The Ames stereo pipeline: NASA's open source software for deriving and processing terrain data. Earth and Space Science, 5(9), 537-548. https://doi.org/10.1029/2018EA000409

Cintala, M. J., \& Mouginis-Mark, P. J. (1980). Martian fresh crater depths: More evidence for subsurface volatiles? Geophysical Research Letters, 7(5), 329-332. https://doi.org/10.1029/GL007i005p00329

Comer, R. P., Solomon, S. C., \& Head, J. W. (1995). Mars: Thickness of the lithosphere from the tectonic response to volcanic loads. Reviews of Geophysics, 23(1), 61-92. https://doi.org/10.1029/RG023i001p00061

Daubar, I. J., Atwood-Stone, C., Byrne, S., McEwen, A. S., \& Russell, P. S. (2014). The morphology of small fresh craters on Mars and the Moon. Journal of Geophysical Research: Planets, 119, 2620-2639. https://doi.org/10.1002/2014JE004671

Dickson, J. L., L. A. Kerber, C. F. L. A. Planetary (2018), A global, blended CTX mosaic of Mars with vectorized seam mapping: A new mosaicking pipeline using principles of non-destructive image editing, LPSC 49, \#2480.

Fassett, C. I., \& Head, J. W. III (2005). Fluvial sedimentary deposits on Mars: Ancient deltas in a crater lake in the Nili fossae region. Geophysical Research Letters, 32, L14201. https://doi.org/10.1029/2005GL023456

Goudge, T. A., Milliken, R. E., Head, J. W., Mustard, J. F., \& Fassett, C. I. (2017). Sedimentological evidence for a deltaic origin of the western fan deposit in Jezero crater, Mars and implications for future exploration. Earth and Planetary Science Letters, 458, $357-365$. https://doi.org/10.1016/j.epsl.2016.10.056

Goudge, T. A., Mustard, J. F., Head, J. W., \& Fassett, C. I. (2012). Constraints on the history of open-basin lakes on Mars from the composition and timing of volcanic resurfacing. Journal of Geophysical Research, 117, E00J21. https://doi.org/10.1029/2012JE004115

Goudge, T. A., Mustard, J. F., Head, J. W., Fassett, C. I., \& Wiseman, S. M. (2015). Assessing the mineralogy of the watershed and fan deposits of the Jezero crater paleolake system, Mars. Journal of Geophysical Research: Planets, 120, 775-808. https://doi.org/10.1002/ 2014JE004782

Hartmann, W. (2005). Martian cratering 8: Isochron refinement and the chronology of Mars. Icarus, 174(2), 294-320. https://doi.org/ 10.1016/j.icarus.2004.11.023

Hartmann, W. K., \& Daubar, I. J. (2016). Martian cratering 11. Utilizing decameter scale crater populations to study Martian history. Meteoritics \& Planetary Science, 52, 493-510. https://doi.org/10.1111/maps.12807

Hiesinger, H., \& Head, J. W. III (2004). The Syrtis Major volcanic province, Mars: Synthesis from Mars Global Surveyor data. Journal of Geophysical Research, 109, E01004. https://doi.org/10.1029/2003JE002143

Ivanov, B.A. (2001): Mars/Moon cratering ratio estimates, Space Science Reviews 96: 87-104. https://doi.org/10.1023/A:1011941121102

Kneissl, T., van Gasselt, S., \& Neukum, G. (2011). Map-projection-independent crater size-frequency determination in GIS environments - New software tool for ArcGIS. Planetary and Space Science, 59, 1243-1254. https://doi.org/10.1016/j.pss.2010.03.015

Malin, M. C., Bell, J. F. II, Cantor, B. A., Caplinger, M. A., Calvin, W. M., Clancy, R. T., et al. (2007). Context camera investigation on board the Mars Reconnaissance Orbiter. Journal of Geophysical Research, 112, E05S04. https://doi.org/10.1029/2006JE002808

Mangold, N., Poulet, F., Mustard, J. F., Bibring, J. P., Gondet, B., Langevin, Y., et al. (2007). Mineralogy of the Nili fossae region with OMEGA/Mars Express data: 2. Aqueous alteration of the crust. Journal of Geophysical Research, 112, E08S04. https://doi.org/10.1029/ 2006JE002835

McEwen, A., Eliason, E., Bergstrom, J. W., Bridges, N., Hansen, C., Delamere, W. A., et al. (2007). Mars Reconnaissance Orbiter's High Resolution Imaging Science Experiment (HiRISE). Journal of Geophysical Research, 112, E05S02. https://doi.org/10.1029/2005JE002605

McEwen, A. Hansen, C. Bridges, N. Delamere, W. A. Eliason, E. Grant, J. et al. (2003) MRO's High Resolution Imaging Science Experiment (HiRISE): Science expectations, International Conference on Mars, 3217

Melosh, Jay. (2011). Planetary surface processes. s.l. : Cambridge Univ. Press, 2011.

Michael, G. G. (2013). Planetary surface dating from crater size-frequency distribution measurements: Multiple resurfacing episodes and differential isochron fitting. Icarus, 226(1), 885-890. https://doi.org/10.1016/j.icarus.2013.07.004

Michael, G. G., Kneissl, T., \& Neesermann, A. (2016). Planetary surface dating from crater size-frequency distribution measurements: Poisson timing analysis. Icarus, 277, 279-285. https://doi.org/10.1016/j.icarus.2016.05.019

Michael, G. G., \& Neukum, G. (2010). Planetary surface dating from crater size-frequency distribution measurements: Partial resurfacing events and statistical age uncertainty. Earth and Planetary Science Letters, 294(3-4), 223-229. https://doi.org/10.1016/j. epsl.2009.12.041

Mustard, J. F., Ehlmann, B. L., Murchie, S. L., Poulet, F., Mangold, N., Head, J. W., et al. (2009). Composition, morphology and stratigraphy of Noachian crust around the Isidis basin. Journal of Geophysical Research, 114, E00D12. https://doi.org/10.1029/2009JE003349

Pike, R. J. (1981). Meteorite craters: Rim height, circularity, and gravity anomalies. Lunar and Planetary Science, 12, 842-844. 
Robbins, S. J., Antonenko, I., Kirchoff, M. R., Chapman, C. R., Fassett, C. I., Herrick, R. R., et al. (2014). The variability of crater identification among expert and community crater analysts. Icarus, 234, 109-131. https://doi.org/10.1016/j.icarus.2014.02.022

Robbins, S. J., \& Hynek, B. M. (2012). A new global database of Mars impact craters $\geq 1 \mathrm{~km}$ : 2 . Global crater properties and regional variations of the simple-to-complex transition diameter. Journal of Geophysical Research, 117, E06001. https://doi.org/10.1029/ 2011JE003967

Schon, S. C., Head, W., \& Fassett, C. I. (2012). An overfilled lacustrine system and progradational delta in Jezero crater, Mars: Implications for Noachian climate (2012). Planetary and Space Science, 67(1), 28-45. https://doi.org/10.1016/j.pss.2012.02.003

Schultz, R. A., \& Frey, H. V. (1990). A new survey of multiring impact basins on Mars. Journal of Geophysical Research, 95(B9), 14,175-14,189. https://doi.org/10.1029/JB095iB09p14175

Shean, D. A., Alexandrov, O., Moratto, Z. M., Smith, B. E., Joughin, I. R., Porter, C., \& Morin, P. (2016). An automated, open-source pipeline for mass production of digital elevation models (DEMs) from very-high-resolution commercial stereo satellite imagery. ISPRS Journal of Photogrammetry and Remote Sensing, 116, 101-117. https://doi.org/10.1016/j.isprsjprs.2016.03.012

Werner, S. C., \& Tanaka, K. L. (2011). Redefinition of the crater-density and absolute-age boundaries for the chronostratigraphic system of Mars. Icarus, 215(2), 603-607. https://doi.org/10.1016/j.icarus.2011.07.024

Wichman, R. W., \& Schultz, P. H. (1986). Sequence and mechanisms of deformation around the Hellas and Isidis impact basin on Mars. Journal of Geophysical Research, 94(B12), 17,333-17,357. https://doi.org/10.1029/JB094iB12p17333 